University of Wollongong

Research Online

Faculty of Social Sciences - Papers (Archive) Faculty of Arts, Social Sciences \& Humanities

$1-1-2017$

Do aspects of social, emotional and behavioural development in the preschool period predict later cognitive and academic attainment?

David Hammer

University of Wollongong, dah10@uowmail.edu.au

Edward Melhuish

University of Wollongong, melhuish@uow.edu.au

Steven J. Howard

University of Wollongong, stevenh@uow.edu.au

Follow this and additional works at: https://ro.uow.edu.au/sspapers

Part of the Education Commons, and the Social and Behavioral Sciences Commons

Research Online is the open access institutional repository for the University of Wollongong. For further information contact the UOW Library: research-pubs@uow.edu.au 


\title{
Do aspects of social, emotional and behavioural development in the pre-school period predict later cognitive and academic attainment?
}

\author{
Abstract \\ (c) 2017, (c) Australian Council for Educational Research 2017. Some aspects of child non-cognitive \\ development in pre-school have independently been shown to predict academic outcomes in later primary \\ and early high school. However, the extent to which each aspect uniquely predicts these outcomes \\ remains unclear. It is also unclear as to what mechanisms may predict these aspects of non-cognitive \\ development. To address these issues, the current study sought to explore the antecedents to, and the \\ predictive strength of, prominent aspects of early non-cognitive development (e.g. hyperactivity, pro-social \\ behaviour, peer and conduct problems at 4-5 years of age) on children's academic achievement at 6-11 \\ years of age from a large, longitudinal and nationally representative sample. The study found early \\ hyperactivity to be the strongest predictor of academic achievement at age 10-11 years of age. Further, \\ early hostile parenting styles, child's gender, and parental educational levels were the strongest and most \\ consistent predictors of children's non-cognitive development. Findings from this study further clarify the \\ relational nature of aspects of non-cognitive development and academic outcomes, as well as the factors \\ that best predict early non-cognitive development.

\section{Disciplines} \\ Education | Social and Behavioral Sciences

\section{Publication Details} \\ Hammer, D., Melhuish, E. \& Howard, S. (2017). Do aspects of social, emotional and behavioural \\ development in the pre-school period predict later cognitive and academic attainment?. Australian \\ Journal of Education, 61 (3), 270-287.
}


Do aspects of social, emotional and behavioural development in the pre-school period predict later cognitive and academic attainment

Mr David Hammer,

University of Wollongong,

Northfields Ave

WOLLONGONG NSW, AUSTRALIA

Email: dhammer@uow.edu.au

Prof Edward Melhuish

University of Wollongong,

Northfields Ave

WOLLONGONG NSW, AUSTRALIA

Email: melhuish@uow.edu.au

Dr Steven J. Howard

University of Wollongong,

Northfields Ave

WOLLONGONG NSW, AUSTRALIA

Email: stevenh@uow.edu.au 


\begin{abstract}
Some aspects of child social, emotional and behavioural (non-cognitive) development in preschool have independently been shown to predict academic outcomes in later primary and early high school. However, the extent to which each aspect uniquely predicts these outcomes remains unclear. It is also unclear as to what mechanisms may predict these aspects of noncognitive development. To address these issues, the current study sought to explore the antecedents to, and the predictive strength of, prominent aspects of early non-cognitive development (e.g., hyperactivity, pro-social behaviour, peer and conduct problems at 4-5 years of age) on children's academic achievement (at 6-11 years of age) with a large, longitudinal and nationally representative sample. The study found early hyperactivity to be the strongest predictor of academic achievement at age 10-11 years of age. Further, early hostile parenting styles, child's gender, and parental educational levels were the strongest and most consistent predictors of children's non-cognitive development. Findings from this study further clarify the relational nature of aspects of non-cognitive development and academic outcomes, as well as the factors that best predict early non-cognitive development.
\end{abstract}




\section{Do aspects of social, emotional and behavioural development in the pre-school period predict later cognitive and academic attainment?}

It is well established that demographic factors such as gender (Bussey \& Bandura, 1999; Maguire, Niens, McCann, \& Connolly 2016), birth weight (Gray, Indurkhya, \& McCorrmick, 2004; Hutchinson et al., 2011) and socio-economic background (Sirin, 2005) each relate to children's social, emotional and behavioural ('non-cognitive') development and academic outcomes. Parents/caregivers are also influential in children's outcomes, with research showing predictive strength for level of parental education (Foster, Lambert, Abbott-Shim, McCarty, \& Franze, 2005), parents' age (Geronimus, Korenman, \& Hillemeier, 1994) and parenting styles (hostile parenting in particular; Grolnick \& Ryan, 1989; Heckman, Stixrud \& Urzua, 2006). While there are various additional individual, demographic and familial factors that have also been posited to influence non-cognitive development (e.g., gestational age, parental depression, parental smoking; Clarke et al., 2012; Gardner et al., 2004; Rosenthal \& Weitzman, 2011), these are often less consistent, robust or predictive in their associations to later outcomes. The importance of non-cognitive development - which includes, but is not limited to, hyperactivity, conduct problems, peer problems, pro-social behaviours, and emotional problems (e.g., Gross, 1998; Ponitz, Matthews, \& Morrison, 2009; Trentacosta \& Shaw, 2009) - is that they appear to relate to child outcomes over and above cognitive factors (Carneiro, Crawford, \& Goodman, 2007). This has led some to suggest a need for educators to also support children's non-cognitive development in preschool and formal schooling (Henricsson \& Rydell, 2006; Sammons et al., 2008).

Mounting evidence links early behavioural control, in particular, with later academic outcomes. For instance, hyperactivity - a hallmark symptom of Attention-Deficit/ Hyperactivity Disorder (ADHD) - in the preschool years is associated with comparatively poorer academic outcomes in early adolescence, compared to same-aged peers (Stergiakouli 
et al., 2016). Further, the influence of ADHD in childhood can persist into adulthood, disrupting employment and personal life (Harpin, 2005). Poor academic outcomes are not limited to those children who have been diagnosed with ADHD; similar patterns of academic outcomes occur in children with higher hyperactivity from the general population (Loe \& Feldman, 2007). These influences in early childhood are not limited to academic pursuits, but independently predict impaired social adjustment in adolsecence, even after controlling for child conduct problems (Taylor et al., 1996).

Research has also found links between a child's early emotional regulation and later academic achievement (Howse, Lange, Farran, \& Boyles, 2003; Raver et al., 2011). For instance, a meta-analysis showed children's early attentional issues (i.e., sustained attention, distractibility) and internalizing issues (i.e., anxiety, personality problems, depressive moods) were particularly strong in their prediction of future academic outcomes (Horne \& Packard, 1985). Similarly, in a longitudinal Australian study, Sawyer et al. (2014) found that selfregulation of emotions and task attentiveness at 2-3 years old predicted literacy and numeracy outcomes at 6-7 years of age.

Children's peer relationships have also been linked to their academic acheivement in adolescence (Liem \& Martin, 2011). For instance, early prosocial interactions have been found to have stronger associations with academic outcomes in adolescence than negative behaviours (Caprara et al., 2000). Both externalising (behavioural) and internalising (emotional) problems in Year 1 of a child's schooling have been shown to affect child peer relations, social competence and academic achievement in Year 6 (Henricsson \& Rydell, 2006). Further to this, Malecki and Elliot (2002), when investigating both children's social skills and behavioural problems, found that both correlated with academic outcomes, but only social skills were predictive of later academic outcomes. The influence of peer relationships within the school environment (school connectedness) is not just limited to academic 
outcomes, but also later adolescent mental health and internalizing behaviours (emotional problems), further influencing academic and career choices (Rothan et al, 2009; Shochet, Dadds, Ham, \& Montague, 2006).

While this evidence shows the contribution of non-cognitive factors to academic outcomes, when considered together, greater clarity is needed around the unique and concurrent contributions of these early social, emotional and behavioural aspects of development with later academic outcomes, after controlling for other influential covariates. At present, it is unclear what social, emotional and behavioural factors most strongly predict children's academic and cognitive outcomes and, by extension, factors that may be particularly important for prevention, education and intervention. The current study thus sought to: (1) investigate the concurrent associations between early parental and demographic factors (from as early as birth) on the development of non-cognitive skills in the preschool years (as rated by parents and educators at age 4-5); and (2) investigate concurrent predictive associations between these non-cognitive factors and children's subsequent academic achievement from ages 6 to 11 years (i.e., literacy, reading comprehension, numeracy, as measured by a national standardised educational assessment). This was achieved using a large-scale longitudinal dataset of Australian children. Analyses were also replicated (to evaluate consistency and robustness of findings) to the extent possible using a second cohort of Australian children from the same study. Consistent with previous research it was predicted that the included range of demographic variables would also predict early noncognitive skill development. Given the strength of findings around hyperactivity and its influence on learning and academic achievement, it was further predicted that hyperactivity would provide strong (negative) associations with subsequent academic outcomes. As a consequence, it was not expected that the other non-cognitive factors would provide consistent additional explanatory value beyond that of hyperactivity. 


\section{Method}

\section{Participants}

Data were drawn from the Longitudinal Study of Australian Children (LSAC). LSAC is a nationally representative, longitudinal study of child development, with a slight bias toward children from metropolitan areas (Soloff, Lawrence, \& Johnstone, 2005). Commenced in 2004, the study consists of two cohorts: children followed since birth (B Cohort) and children followed since Kindergarten (K Cohort, 4-5 years old; AIFS, 2013).

The present study used data from the $\mathrm{K}$ Cohort $(N=4,983)$ as its initial sample (girls $=$ 49.1\%) and the B Cohort $(N=5,107)$ as its replication sample (girls $=48.9 \%)$. While slight demographic differences exist between the two cohorts in terms of parental education, disproportionate representation of study children from capital cities and regional centres, and higher rates of international births within the K cohort (AIFS, 2015), these factors were controlled for in analyses. LSAC data were collected every two years over the ten years of data available for this study.

The retention rate for participants from 2004 to 2012 was $79.4 \%$, and further breakdown of sample characteristics is given in AIFS (2013). Missing data were identified as Missing at Random (MAR) from analyses of attrition rates in preceding waves of collection (Nicholson, Deboeck, \& Howard, 2017).

\section{Measures}

Measures were selected from those available within LSAC to capture child and family demographics/characteristics (4-5 years of age), non-cognitive development (4-5 years of age), and subsequent academic outcomes (6-11 years of age). In most cases, other than that explicitly identified as teacher-report data, the demographic, family and non-cognitive data was reported by 'parent 1'. LSAC defines parent 1 as "the person who knows most about the study child, usually biological mother", while "parent 2 is parent 1's partner or other adult in 
the home with a parental relationship to the study child" (AIFS, 2013, p. 9). Biological parental relationships represented $99.3 \%$ (B cohort) and 96.5\% (K cohort) of LSAC families. This rate of biological versus other caregiver relationships (foster parents, other family care givers) is broadly representative of the Australian population (ABS, 2011). Children's academic outcomes were measured by national standardised educational assessments (i.e., NAPLAN) or through commercial standardised assessments (e.g., PPVT).

Demographics/Characteristics (collected at 4-5 years of age). Hostile parenting was indexed by the 5-item self-report Hostile Parenting scale (AIFS, 2013). Items are rated on a 10-point Likert scale $(1=$ 'Not at all' to $10=$ 'All the time', on statements such as 'I have raised my voice with or shouted at this child'), which were averaged to generate a 'hostile parenting' score. Socioeconomic status was indexed by the Socio-Economic Index for Areas (SEIFA) Relative Advantage/Disadvantage scale, developed by the Australian Bureau of Statistics, which captures aspects of socioeconomic status at an area level, including typical income, education, employment, occupation, and housing within the area (Pink, 2013). To assess the level of education of the mother (parent 1) and father (parent 2) a 6-point Likert scale was used to identify highest level of education completed $(1=$ 'less than Year 12 ' to $6=$ 'post-graduate studies'). For the current study, other demographic characteristics considered were the child's birth weight, gender, and mother's age at time of birth.

Non-cognitive development (collected at 4-5 years of age). Children's social, emotional and behavioural development was measured using educator and parent ratings on the Strengths and Difficulties Questionnaire (SDQ; Goodman, 1997). Both parent and educator ratings were used given the common disparity in evaluations of a child's social and behavioural development across environments and raters (Antrop, Roeyers, Oosteriann, \& VanOost, 2002) and the finding that each rating source may predict different outcomes (Sharp, Croudace, Goodyer, \& Amtmann, 2005). The SDQ is a 25-item scale, with the 
following five subscales (each comprised of five items): prosocial behaviour (e.g., 'the child shares readily with other children'), conduct problems (e.g., 'the child often fights with other children'), hyperactivity (e.g., 'the child is easily distracted and concentration wanders'), peer problems (e.g., 'other children or young people pick on or bully the child'), and emotional problems (e.g., 'child worries a lot'). All items were rated on a Likert scale ranging from 0 (Not true) to 2 (Certainly true). The SDQ has acceptable internal consistency for use with this age group ( $a=.73$; Goodman, 2001).

Cognitive and Academic Outcomes (collected at 6-11 years of age). The 23-item version of the Peabody Picture Vocabulary Test $3^{\text {rd }}$ edition (PPVT-III; Dunn \& Dunn, 1997) was adopted as a measure of language development. For this measure, children are presented with a series of pictures and the child is asked to recognise the picture corresponding to a spoken word (Dunn \& Dunn, 1997). The PPVT-III has good reliability ( $a=.76$; Rothman, 2003). Academic outcomes were assessed in each of Years 3, 5, and 7 using the National Assessment Program - Literacy and Numeracy assessment (NAPLAN; ACARA, 2013). It is a national standardised assessment for Australia, administered to all students every other year from Year 3 to Year 9, with assessments of reading, writing, language conventions, and numeracy. Results for reading, writing, spelling, grammar and punctuation (combined as a literacy index) and numeracy were considered for the purposes of this study.

\section{Results}

\section{Antecedents of Non-cognitive Behaviours}

To investigate the antecedents of children's non-cognitive behaviours at age 4-5 years, linear regressions were undertaken using K cohort SDQ subscales as outcome variables, as rated by parents and teachers. Correlations amongst SDQ subscales ranged from: $r=.12$ to .48 for parent ratings; from $r=.13$ to .57 for teacher ratings; and from $r=.18$ to .37 between parent and teacher ratings of the same subscale. Predictors of non-cognitive behaviours were 
hostile parenting, maternal age, SEIFA, educational attainment of the mother and father, child's birth weight and child gender. All regressions were replicated, to the extent possible, with the B cohort to confirm initial findings. All predictor standardized beta $(\beta)$ weights and $p$ values are reported in Table 2. Results are summarised below.

Emotional problems. A regression on parent-rated emotional problems indicated hostile parenting and maternal age were associated with emotional problems at 4-5 years of age. These predictors were also significant within the B cohort, with child's gender additionally associated with emotional problems in this cohort. None of the variables investigated, however, predicted teacher ratings of emotional problems at 4-5 years of age.

Conduct problems. The regression on parent ratings of child conduct problems at age 45 years showed strong effect sizes for hostile parenting, and more modest effect sizes for maternal education and SES. Replication with the B cohort showed comparable results, except maternal education was no longer a significant predictor. Results for teacher ratings of conduct problems also indicated father's hostile parenting and child's gender as significant predictors, with modest effect sizes. Replication with the B cohort saw the addition of mother's hostile parenting style as a significant predictor, albeit with a small effect size.

Hyperactivity. The regression on parent ratings of hyperactivity showed hostile parenting, maternal education, maternal age, birth weight and the child's gender as significant predictors of hyperactivity at age 4-5 years. Moderate effect sizes were shown between these predictors and hyperactivity. Replication in the B cohort yielded the addition of paternal education and removal of birth weight as significant predictors. The regression on teacher ratings of hyperactivity showed that hostile parenting, birth weight, maternal education and gender were significant predictors of hyperactivity, albeit with weak effect sizes. Replication with the B cohort indicated only father's hostile parenting and gender as significant predictors of hyperactivity. 
Peer problems. The regression on parent ratings of child peer problems showed that mother's hostile parenting, SES, maternal education and child's gender were significant predictors of peer problems at age 4-5 years, with weak to moderate effect sizes. The B cohort replication had the same set of significant predictors, with the exception of maternal education. Teacher rating regressions were predicted by mother's hostile parenting and child's gender, but only within the K cohort.

Prosocial Behaviours. The regression on parent ratings of prosocial behaviour showed that hostile parenting, parental education, and child gender were significant predictors of prosocial behaviours at age 4-5. Effect sizes for the regression were shown to be moderate. B cohort results added maternal age and eliminated parental education as significant predictors in this cohort, again showing moderate effect sizes. Regression on teacher ratings of prosocial behaviours supported father's hostile parenting, maternal age, birth weight and the child's gender as significant predictors of prosocial behaviour. Replication in the B cohort indicated only mother's and father's hostile parenting and gender as significant predictors.

Summary. Most of the antecedents suggested in the literature were significant predictors of social, emotional and behavioural development at age 4-5 years, in at least some of the regressions. However, few were consistent and robust predictors. Hostile parenting was a particularly consistent and strong predictor, with modest effect sizes being recorded for all non-cognitive factors. This was typically the case for both parent- and educator-ratings, suggesting that this association is likely not simply confounding general parental beliefs and biases within their ratings of their child's non-cognitive development. Also consistent was child gender. SES and maternal education were less consistently significant, particularly for teacher ratings. 
Table 2.1

Correlations between Socio-behavioural (non-cognitive) Indices for Parent and Teacher Ratings, by Cohort

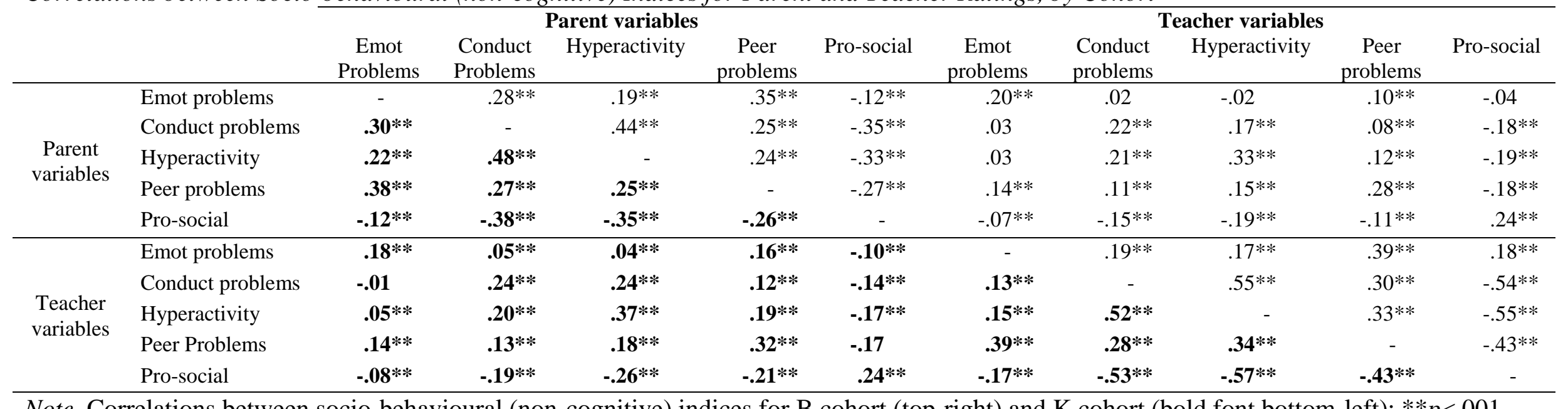

Note. Correlations between socio-behavioural (non-cognitive) indices for B cohort (top-right) and K cohort (bold font bottom-left); ** $p<.001$ 
Table 2.2

Predictors of Parent and Teacher ratings of socio-behavioural outcomes at age 4-5

\begin{tabular}{|c|c|c|c|c|c|c|c|c|c|c|c|c|}
\hline & \multicolumn{6}{|c|}{ K cohort } & \multicolumn{6}{|c|}{ B Cohort } \\
\hline & \multicolumn{3}{|c|}{ Parent } & \multicolumn{3}{|c|}{ Teacher } & \multicolumn{3}{|c|}{ Parent } & \multicolumn{3}{|c|}{ Teacher } \\
\hline & $B$ & $S E$ & $\beta$ & $B$ & $S E$ & $\beta$ & $B$ & $S E$ & $\beta$ & $B$ & $S E$ & $\beta$ \\
\hline \multicolumn{13}{|l|}{ Emot Problems } \\
\hline P1 Hostile parent & .57 & .07 & $.21 * *$ & - & - & - & .20 & .03 & $.16^{* *}$ & - & - & - \\
\hline P2 Hostile parent & .14 & .06 & $.05^{*}$ & - & - & - & .03 & .03 & .02 & - & - & - \\
\hline Maternal age & -.02 & .01 & $-.07 *$ & - & - & - & -.02 & .01 & $-.07 * *$ & - & - & - \\
\hline Child birth weight & .00 & .00 & $-.05^{*}$ & - & - & - & .00 & .00 & -.02 & - & - & - \\
\hline SEIFA adv/disadv & .00 & .00 & -.01 & - & - & - & .00 & .00 & -.03 & - & - & - \\
\hline P1 Highest qual & .04 & .03 & .04 & - & - & - & .01 & .03 & .01 & - & - & - \\
\hline P2 Highest qual & .00 & .03 & .00 & - & - & - & -.02 & .02 & -.02 & - & - & - \\
\hline Gender & -.01 & .07 & -.01 & - & - & - & .21 & .07 & $.07 *$ & - & - & - \\
\hline \multicolumn{13}{|l|}{ Condct Problems } \\
\hline P1 Hostile parent & 1.39 & .07 & $.42 * *$ & .14 & .08 & .05 & .52 & .03 & $.37 * *$ & .09 & .04 & $.07 *$ \\
\hline P2 Hostile parent & .52 & .07 & $.17 * *$ & .39 & .08 & $.14 * *$ & .20 & .03 & $.14 * *$ & .09 & .04 & $.07 *$ \\
\hline Maternal age & -.01 & .01 & -.02 & .00 & .01 & .01 & -.01 & .01 & -.01 & .00 & .01 & .00 \\
\hline Child birth weight & .00 & .00 & -.02 & .00 & .00 & -.04 & .00 & .00 & .01 & .00 & .00 & .00 \\
\hline SEIFA adv/disadv & .00 & .00 & $-.06 *$ & .00 & .00 & -.03 & .00 & .00 & $-.09 * *$ & .00 & .00 & -.02 \\
\hline P1 Highest qual & .08 & .03 & $.06 *$ & .04 & .04 & .04 & -.03 & .03 & -.03 & -.02 & .03 & -.02 \\
\hline P2 Highest qual & .02 & .03 & .01 & .03 & .04 & .03 & .05 & .03 & .04 & .01 & .03 & .01 \\
\hline Gender & -.01 & .08 & .00 & -.36 & .09 & $-.11 * *$ & -.05 & .07 & -.02 & -.41 & .09 & $-.12 * *$ \\
\hline \multicolumn{13}{|l|}{ Hyperactivity } \\
\hline P1 Hostile parent & 1.05 & .08 & $.28 * *$ & .42 & .12 & $.10 * *$ & .38 & .04 & $.23 * *$ & .09 & .05 & .05 \\
\hline P2 Hostile parent & .47 & .08 & $.13 * *$ & .38 & .12 & $.09 * *$ & .14 & .04 & $.08 * *$ & .10 & .05 & $.06 *$ \\
\hline Maternal age & -.04 & .01 & $-.08 * *$ & .01 & .02 & .02 & -.03 & .01 & $-.07 *$ & .01 & .01 & .02 \\
\hline Child birth weight & .00 & .00 & $-.08 * *$ & .00 & .00 & $-.09 * *$ & .00 & .00 & -.02 & .00 & .00 & -.04 \\
\hline SEIFA adv/disadv & .00 & .00 & -.01 & .00 & .00 & .02 & .00 & .00 & -.03 & .00 & .00 & .01 \\
\hline P1 Highest qual & .23 & .04 & $.15^{* *}$ & .12 & .05 & $.06^{*}$ & .08 & .04 & $.06^{*}$ & .08 & .05 & .05 \\
\hline P2 Highest qual & .04 & .04 & .02 & .05 & .05 & .03 & .07 & .03 & $.05 *$ & .05 & .04 & .03 \\
\hline Gender & -.67 & .09 & $-.15 * *$ & -1.21 & .13 & $-.25 * *$ & -.66 & .09 & $-.16^{* *}$ & -1.11 & .11 & $-.25^{* *}$ \\
\hline \multicolumn{13}{|l|}{ Peer Problems } \\
\hline P1 Hostile parent & .44 & .06 & $.17 * *$ & .25 & .08 & $.08^{*}$ & .13 & .03 & $.11^{* *}$ & - & - & - \\
\hline P2 Hostile parent & .03 & .06 & .01 & .08 & .08 & .03 & .01 & .03 & .01 & - & - & - \\
\hline Maternal age & .00 & .01 & -.01 & -.01 & .01 & -.02 & -.01 & .01 & -.04 & - & - & - \\
\hline Child birth weight & .00 & .00 & -.02 & .00 & .00 & -.05 & .00 & .00 & -.03 & - & - & - \\
\hline SEIFA adv/disadv & .00 & .00 & $-.07 *$ & .00 & .00 & -.04 & .00 & .00 & $-.07 *$ & - & - & - \\
\hline P1 Highest qual & .08 & .03 & $.07 *$ & .03 & .04 & .03 & .00 & .03 & .00 & - & - & - \\
\hline P2 Highest qual & .01 & .03 & .01 & .04 & .04 & .04 & .00 & .03 & .00 & - & - & - \\
\hline Gender & -.26 & .07 & $-.09 * *$ & -.42 & .09 & $-.13 * *$ & -.17 & .07 & $.06^{*}$ & - & - & - \\
\hline \multicolumn{13}{|l|}{ Prosoc behaviour } \\
\hline P1 Hostile parent & -.81 & .07 & $-.26 * *$ & -.21 & .11 & -.05 & -.31 & .03 & $-.21 * *$ & -.11 & .05 & $-.06 *$ \\
\hline P2 Hostile parent & -.26 & .07 & $-.09 * *$ & -.47 & .11 & $-.12 * *$ & -.07 & .04 & $-.05 *$ & -.10 & .05 & $-.06 *$ \\
\hline Maternal age & -.01 & .01 & -.03 & -.04 & .01 & $-.07 *$ & -.03 & .01 & $-.09 * *$ & -.01 & .01 & -.02 \\
\hline Child birth weight & .00 & .00 & .01 & .00 & .00 & $.06 *$ & .00 & .00 & -.02 & .00 & .00 & -.01 \\
\hline SEIFA adv/disadv & .00 & .00 & .02 & .00 & .00 & .06 & .00 & .00 & .02 & .00 & .00 & .02 \\
\hline P1 Highest qual & -.07 & .03 & $-.05 *$ & -.09 & .05 & -.05 & .02 & .03 & .02 & -.01 & .05 & -.01 \\
\hline P2 Highest qual & .06 & .03 & $.05 *$ & .03 & .05 & .02 & -.01 & .03 & -.01 & -.04 & .04 & -.02 \\
\hline Gender & .43 & .08 & $.12 * *$ & 1.05 & .13 & $.23^{* *}$ & .52 & .08 & $.15^{* *}$ & 1.01 & .12 & $.23 * *$ \\
\hline
\end{tabular}

Note. $B=$ unstandardized regression weights, $S E=$ Standard error, $\beta=$ standardized regression weights. P1 = mother. $\mathrm{P} 2=$ father. $* p<.05 ; * * p<.001$ 


\section{Non-cognitive Development and Later Cognitive and Academic Outcomes}

To investigate the prediction of cognitive and academic outcomes from earlier noncognitive development, stepwise hierarchical regressions (Tabachnick \& Fidell, 2013) were undertaken. Step 1 included all antecedent predictors included in the previous analyses. Step 2 contained both parent and teacher ratings of child non-cognitive development. Academic measures were NAPLAN literacy and NAPLAN numeracy at Year 3 (B cohort $M_{\text {age }}=8.49$ years; $\mathrm{K}$ cohort $M_{\text {age }}=8.64$ years $)$, Year $5\left(\mathrm{~K}\right.$ cohort $M_{\text {age }}=10.47$ years $)$, and Year $7(\mathrm{~K}$ cohort $M_{\text {age }}=12.42$ years) were used as outcome variables. In addition, receptive vocabulary as measured by Peabody Picture Vocabulary Test (PPVT) was available at Year 1 (B cohort $M_{\text {age }}=6.32$ years $; \mathrm{K}$ cohort $M_{\text {age }}=6.29$ years $)$ and Year $3\left(\mathrm{~B}\right.$ cohort $M_{\text {age }}=8.39$ years; $\mathrm{K}$ cohort $M_{\text {age }}=8.29$ years). A series of regressions were again undertaken in the $\mathrm{K}$ cohort, and where possible replicated in the B cohort for Year 3 only, as this was the only corresponding data available for this cohort. All predictor standardized beta weights $(\beta)$ and $p$ values are reported in Tables 3-5. Results are summarised below.

Peabody Picture Vocabulary Test (PPVT). In separate regressions predicting PPVT scores in Year 3 (6-7 years) and Year 5 (8-9 years), significant predictors in both regressions were teacher ratings of hyperactivity, with small to moderate effect sizes (see Table 3). Teacher ratings of conduct problems, peer problems and prosocial behavior were also significant for PPVT scores at 6-7 years, but not 8-9 years. Parental education, birth weight, and child's gender were also significant covariates. Replication in the B cohort showed conduct problems and hyperactivity as significant predictors of PPVT scores at age 6-7 years. Also significant were parental ratings of prosocial behaviour.

NAPLAN Literacy. In separate regressions predicting NAPLAN literacy scores, teacher ratings of hyperactivity were again significant with moderate predicative strength at all Years (Table 4). Also significant were parent ratings of hyperactivity (for Year 7), prosocial 
behaviours and emotional problems (for Year 5), and peer problems (for Years 3 and 7), with small effect sizes across all these variables. Teacher ratings of peer problems were also significant for Year 3. Significant covariates across all Years were parental education, SES and child's gender (with small to moderate effect sizes), while mother's hostile parenting was also significant only for Year 5 NAPLAN literacy scores. Replication in the B cohort for Year 3 showed that only teacher-rated hyperactivity remained significant, while parent-rated hyperactivity became significant. The same complement of covariates, plus the addition of child gender, also was significant. Effect sizes were reflective of the previous relationships ranging from small to moderate.

NAPLAN Numeracy. In separate regressions predicting NAPLAN numeracy scores, parent and teacher ratings of hyperactivity were significant for all Years, with small to moderate effect sizes. Also significant for Year 3 were parent ratings of peer problems. Significant covariates were parental education, SES and maternal age. Hostile parenting and child's gender also became significant predictors of Year 5 and 7 NAPLAN numeracy scores, although effect sizes were small to moderate. Replication in the B cohort for Year 3 showed the same complement of predictors, with the addition of birth weight and child's gender as significant predictors. Parent-rated peer problems and maternal age were no longer significant.

Summary. As expected, the most common non-cognitive factor predicting later academic outcomes was hyperactivity. This was most common in teacher ratings, but in some cases (e.g., for numeracy) parent ratings contributed added and unique predictive strength. While most other factors showed some significant prediction of academic outcomes, these were far less consistent or robust. 
Table 2.3

Predictors of PPVT vocabulary scores, by cohort

\begin{tabular}{|c|c|c|c|c|c|c|c|c|c|c|c|c|c|c|c|c|}
\hline & \multicolumn{8}{|c|}{ Age 6-7 } & \multicolumn{8}{|c|}{ Age 8-9 } \\
\hline & \multicolumn{4}{|c|}{ K Cohort $(n=1152)$} & \multicolumn{4}{|c|}{ B Cohort $(n=1260)$} & \multicolumn{3}{|c|}{ K Cohort $(n=1176)$} & \multicolumn{5}{|c|}{ B Cohort $(n=1223)$} \\
\hline & Adj $R^{2}$ & $B$ & $S E$ & $\beta$ & Adj $R^{2}$ & $B$ & $S E$ & $\beta$ & Adj $R^{2}$ & $B$ & $S E$ & $\beta$ & Adj $R^{2}$ & $B$ & $S E$ & $\beta$ \\
\hline Demographics & .05 & & & & .04 & & & & .07 & & & & .07 & & & \\
\hline P1 Highest qual & & -.26 & .11 & $-.07 *$ & & -.34 & .11 & $-.09 *$ & & -.33 & .11 & $-.09 *$ & & -.41 & .10 & $-.12 * *$ \\
\hline P2 Highest qual & & -.36 & .11 & $-.11 * *$ & & -.30 & .10 & $-.09 *$ & & -.50 & .10 & $-.15 * *$ & & -.35 & .10 & $-.11 * *$ \\
\hline SEIFA Adv/Disav & & .00 & .00 & .05 & & .01 & .00 & $.07 *$ & & .00 & .00 & $.06^{*}$ & & .01 & .00 & $.10 * *$ \\
\hline Child birth weight & & .00 & .00 & $.10 * *$ & & .00 & .00 & .03 & & .00 & .00 & $.07 *$ & & .00 & .00 & .03 \\
\hline Maternal age & & .05 & .03 & .05 & & .04 & .03 & .04 & & .08 & .03 & $.07 *$ & & .03 & .03 & .03 \\
\hline P1 Hostile parent & & -.13 & .30 & -.02 & & -.05 & .13 & -.01 & & .04 & .28 & .01 & & -.12 & .12 & -.03 \\
\hline P2 Hostile parent & & -.02 & .26 & .00 & & -.09 & .12 & -.02 & & .41 & .25 & .05 & & -.04 & .12 & -.01 \\
\hline Gender & & -1.01 & .30 & $-.10 * *$ & & -.77 & .29 & $-.08 *$ & & -.47 & .29 & -.05 & & -1.10 & .27 & $-.12 * *$ \\
\hline $\begin{array}{l}\text { Soc-Emo-Behav. } \\
\text { SDQ Parent }\end{array}$ & .07 & & & & .06 & & & & .08 & & & & .09 & & & \\
\hline Emot problems & & -.03 & .10 & -.01 & & .15 & .10 & -.04 & & -.11 & .10 & -.03 & & -.09 & .10 & -.03 \\
\hline Conduct problems & & -.03 & .10 & -.01 & & .11 & .10 & .04 & & .01 & .09 & .00 & & .08 & .10 & .03 \\
\hline Hyperactivity & & -.03 & .08 & -.01 & & -.14 & .08 & -.06 & & -.07 & .08 & -.03 & & -.05 & .08 & -.02 \\
\hline Peer problems & & -.10 & .11 & -.03 & & .07 & .12 & .02 & & .00 & .11 & .00 & & -.03 & .11 & -.01 \\
\hline Pro-social & & .04 & .09 & .01 & & .19 & .09 & $.07 *$ & & .04 & .09 & .02 & & .16 & .09 & .06 \\
\hline$S D Q$ Teacher & & & & & & & & & & & & & & & & \\
\hline Emot problems & & -.04 & .10 & -.01 & & -.03 & .10 & -.01 & & -.02 & .10 & -.01 & & -.05 & .10 & -.02 \\
\hline Conduct problems & & .38 & .11 & $.13 * *$ & & .28 & .11 & $.09 *$ & & .15 & .10 & .05 & & .33 & .10 & $.12 * *$ \\
\hline Hyperactivity & & -.25 & .08 & $-.12 * *$ & & -.18 & .08 & $-.08 *$ & & -.15 & .07 & $-.08 *$ & & -.21 & .08 & $-.10^{*}$ \\
\hline Peer problems & & .23 & .10 & $.08 *$ & & -.15 & .11 & -.05 & & -.06 & .10 & -.02 & & -.14 & .10 & -.05 \\
\hline Pro-social & & .28 & .08 & $.13 * *$ & & .07 & .08 & .03 & & .14 & .08 & .07 & & .11 & .08 & .05 \\
\hline
\end{tabular}

Note. $B=$ unstandardized regression weights, $S E=$ Standard error, $\beta=$ standardized regression weights. $\mathrm{P} 1=$ mother. $\mathrm{P} 2=$ father. $* p<.05 ; * * p<.001$ 
Table 2.4

Predictors of NAPLAN Literacy (K cohort), by Year

\begin{tabular}{|c|c|c|c|c|c|c|c|c|c|c|c|c|}
\hline & \multicolumn{4}{|c|}{ Year $3(n=838)$} & \multicolumn{4}{|c|}{ Year $5(n=1085)$} & \multicolumn{4}{|c|}{ Year $7(n=1003)$} \\
\hline & $\operatorname{Adj} R^{2}$ & $B$ & $S E$ & $\beta$ & $\operatorname{Adj} R^{2}$ & $B$ & $S E$ & $\beta$ & Adj $R^{2}$ & $B$ & $S E$ & $\beta$ \\
\hline Demographics & .10 & & & & .13 & & & & .16 & & & \\
\hline P1 Highest Qual & & -5.18 & 1.74 & $-.11 * *$ & & -4.39 & 1.40 & $-.09 *$ & & -4.25 & 1.34 & $-.10 * *$ \\
\hline P2 Highest Qual & & -7.71 & 1.63 & $-.17 * *$ & & -8.28 & 1.34 & $-.19 * *$ & & -9.39 & 1.28 & $-.23 * *$ \\
\hline SEIFA adv/disadv & & .10 & .03 & $.11 * *$ & & .10 & .02 & $.13 * *$ & & .07 & .02 & $.10^{* *}$ \\
\hline Child's birth weight & & .00 & .00 & .02 & & .00 & .00 & .02 & & .00 & .00 & .02 \\
\hline Maternal Age & & .65 & .52 & .04 & & .61 & .41 & .04 & & .65 & .39 & .05 \\
\hline P1 Hostile Parent & & 8.29 & 4.52 & .07 & & 10.66 & 3.61 & $.10 *$ & & 8.80 & 3.42 & $.09 *$ \\
\hline P2 Hostile Parent & & .16 & 4.05 & .00 & & .57 & 3.29 & .01 & & -.74 & 3.16 & -.01 \\
\hline Gender & & 5.54 & 4.59 & .04 & & 12.17 & 3.70 & $.10^{* *}$ & & 16.56 & 3.53 & $.14^{* *}$ \\
\hline $\begin{array}{l}\text { Soc-Emo-Behav. } \\
S D Q \text { Parent }\end{array}$ & .19 & & & & .20 & & & & .22 & & & \\
\hline Emot Problems & & .02 & 1.57 & .00 & & -2.49 & 1.27 & $-.06 *$ & & -1.57 & 1.23 & -.04 \\
\hline Conduct Problems & & -2.23 & 1.47 & -.06 & & -.30 & 1.21 & -.01 & & -.60 & 1.15 & -.02 \\
\hline Hyperactivity & & -1.51 & 1.21 & -.05 & & -1.88 & 1.00 & -.06 & & -3.13 & .98 & $-.11 * *$ \\
\hline Peer Problems & & 4.31 & 1.69 & $.09 *$ & & 2.57 & 1.39 & .06 & & 3.53 & 1.33 & $.08^{*}$ \\
\hline Pro-social & & 1.64 & 1.41 & .04 & & 2.56 & 1.14 & $.07 *$ & & 1.76 & 1.09 & .05 \\
\hline$S D Q$ Teacher & & & & & & & & & & & & \\
\hline Emot Problems & & .31 & 1.67 & .01 & & -.26 & 1.26 & -.01 & & -1.42 & 1.20 & -.04 \\
\hline Conduct Problems & & .51 & 1.68 & .01 & & .80 & 1.31 & .02 & & .98 & 1.27 & .03 \\
\hline Hyperactivity & & -7.25 & 1.24 & $-.25 * *$ & & -6.94 & .95 & $-.27 * *$ & & -5.24 & .92 & $-.21 * *$ \\
\hline Peer Problems & & -3.16 & 1.54 & $.08 *$ & & .67 & 1.26 & .02 & & 1.45 & 1.20 & .04 \\
\hline Pro-social & & -.56 & 1.25 & -.02 & & -1.38 & 1.02 & -.05 & & -.40 & .99 & -.02 \\
\hline
\end{tabular}


Table 2.5

Predictors of NAPLAN Numeracy (K cohort), by Year

\begin{tabular}{|c|c|c|c|c|c|c|c|c|c|c|c|c|}
\hline & \multicolumn{4}{|c|}{ Year 3 $(n=837)$} & \multicolumn{4}{|c|}{ Year $5(n=1073)$} & \multicolumn{4}{|c|}{ Year $7(n=996)$} \\
\hline & $\operatorname{Adj} R^{2}$ & $B$ & $S E$ & $\beta$ & Adj $R^{2}$ & $B$ & $S E$ & $\beta$ & Adj $R^{2}$ & $B$ & $S E$ & $\beta$ \\
\hline Demographics & .09 & & & & .09 & & & & .11 & & & \\
\hline P1 Highest Qual & & -4.78 & 1.80 & $-.09 *$ & & -3.32 & 1.67 & $-.06 *$ & & -4.75 & 1.74 & $-.09 *$ \\
\hline P2 Highest Qual & & -6.88 & 1.69 & $-.15 * *$ & & -7.88 & 1.59 & $-.16 * *$ & & -10.18 & 1.66 & $-.20 * *$ \\
\hline SEIFA adv/disadv & & .06 & .03 & $.07 *$ & & .13 & .03 & $.15^{* *}$ & & .10 & .03 & $.11 * *$ \\
\hline Child's birth weight & & .00 & .00 & .04 & & .00 & .00 & .01 & & .00 & .00 & .03 \\
\hline Maternal Age & & 1.47 & .54 & $.09 *$ & & .06 & .49 & .00 & & .03 & .51 & .00 \\
\hline P1 Hostile Parent & & 4.42 & 4.68 & .04 & & 12.84 & 4.30 & $.10^{*}$ & & 13.31 & 4.48 & $.10^{*}$ \\
\hline P2 Hostile Parent & & 6.75 & 4.19 & .06 & & .80 & 3.92 & .01 & & -.86 & 4.11 & -.01 \\
\hline Gender & & -7.02 & 4.76 & -.05 & & -17.27 & 4.40 & $-.12 * *$ & & -13.98 & 4.58 & $-.09 *$ \\
\hline $\begin{array}{l}\text { Soc-Emo-Behav. } \\
\text { SDQ Parent ratings }\end{array}$ & .15 & & & & .13 & & & & .16 & & & \\
\hline Emot Problems & & -.70 & 1.62 & -.02 & & -1.23 & 1.51 & -.03 & & -.49 & 1.60 & -.01 \\
\hline Conduct Problems & & -2.05 & 1.53 & -.06 & & -.85 & 1.44 & -.02 & & -.63 & 1.51 & -.02 \\
\hline Hyperactivity & & -2.56 & 1.25 & $-.08 *$ & & -2.70 & 1.19 & $-.08 *$ & & -5.16 & 1.28 & $-.15 * *$ \\
\hline Peer Problems & & 3.48 & 1.75 & $.07 *$ & & 2.27 & 1.66 & .04 & & 3.20 & 1.74 & .06 \\
\hline Pro-social & & 1.45 & 1.46 & .04 & & 1.60 & 1.36 & .04 & & .74 & 1.41 & .02 \\
\hline$S D Q$ Teacher ratings & & & & & & & & & & & & \\
\hline Emot Problems & & -2.02 & 1.73 & -.04 & & -1.23 & 1.50 & -.03 & & -2.71 & 1.58 & -.06 \\
\hline Conduct Problems & & 1.75 & 1.74 & .04 & & -.17 & 1.56 & -.00 & & .21 & 1.65 & .01 \\
\hline Hyperactivity & & -6.32 & 1.28 & $-.21 * *$ & & -6.50 & 1.13 & $-.22 * *$ & & -6.22 & 1.20 & $-.20 * *$ \\
\hline Peer Problems & & -.01 & 1.60 & .00 & & 1.44 & 1.50 & .03 & & 1.66 & 1.57 & .04 \\
\hline Pro-social & & -.04 & 1.30 & .00 & & -1.68 & 1.21 & -.05 & & -1.60 & 1.29 & -.05 \\
\hline
\end{tabular}

Note. $B=$ unstandardized regression weights, $S E=$ Standard error, $\beta=$ standardized regression weights. P1 = mother. P2 = father. Analyses were replicated with the B cohort at Year 3 (the only available NAPLAN data) - significant betas in the B cohort replication are bolded. *p<.05; **p<.001 


\section{Discussion}

Firstly, the current study examined children's non-cognitive development at age 4-5 years to identify concurrent associations amongst antecedents that had previously been suggested in the literature, but often not considered concurrently. Subsequent analyses examined how these non-cognitive factors might predict, when considered concurrently, later academic outcomes. Results indicated that hostile parenting, child gender and SES were strong predictors of a range of non-cognitive factors. Previously identified antecedents, such as maternal age and child's birth weight, added minimal additional predictive strength when considered concurrently with these other factors. After controlling for these antecedents, teacher-rated hyperactive behaviours predicted a wide range of subsequent academic outcomes, up to five years later. Less explanatory value was provided by other non-cognitive variables, such as conduct problems, peer problems, or emotional problems. Overall, these results suggested that: (a) non-cognitive factors were associated with potentially modifiable (e.g., hostile parenting, parental education, SES) and non-modifiable (e.g. gender, birth weight, maternal age) environmental factors and (b) non-cognitive factors, and in particular hyperactive behaviour, may be a viable target for intervention to enhance subsequent academic performance. Targeting other non-cognitive factors (e.g., conduct problems) may also generate a positive impact, but the current results suggested these might have morelimited impact on academic proficiency and progress.

Several antecedents predicted children's non-cognitive development (i.e., hyperactivity, prosocial behaviours, emotional, conduct, and peer problems). One such antecedent was hostile parenting, which was associated with each of the outcomes, even when controlling for other important covariates (e.g., parental education, SES). More harsh or hostile parenting practices were associated with higher adult-rated socio-emotional problems at age 4-5. This is consistent with, albeit in this case earlier than, results from Anthony et al. (2005) of negative 
relationships between harsh parenting, social competence, and prosocial behaviours amongst primary school children. Of additional interest is that hostile parenting was more consistently related to parent ratings of children's non-cognitive development, suggesting that there may be some underlying beliefs and biases that influence parent ratings of their parenting and their child's development. This is consistent with evidence that parenting not only influences children's social, emotional and behavioural development (e.g., Chang, Schwartz, Dodge, \& McBride-Chang, 2003), but also that children's temperament and behavour may also influence parenting practices (Clark, Kochanska, \& Ready, 2000). Nonetheless, that parents' ratings of their hostile parenting practices also predicted most teacher-rated non-cognitive factors suggests that this likely is an important factor in a possible causal sequence.

Gender and parental education were also relatively consistent in their predictive strength of early non-cognitive development, although again more highly for parent than teacher rated development. That these factors were significant even after accounting for hostile parenting practices is consistent with previous research on differences in the early social, emotional and behavioural development of boys and girls (Miller, Koplewicz, \& Klein, 1997) and the influential role of parental education (McLoyd, 1998; Sirin, 2005). In the present study, parental education was included as a separate predictor from SES to determine its independent association with child non-cognitive development. In doing so, maternal education was shown to be an independent and stronger predictor of a child's noncognitive development than SES. This finding thus helps to clarify parents' education level and by extension, their practices (Belsky, Bell, Bradley, Stallard, \& Stewart-Brown, 2007) as likely being more influential on their child's socio-behavioural development than simply their socioeconomic means (albeit the two are undoubtedly conflated; Davis-Kean, 2005; Eamon, 2001). 
The predictive strength of other demographic and contextual factors showed relationships similar to those found in prior research, albeit with lower and less consistent predictive strength, after controlling for hostile parenting style, gender and parental education. That is, maternal age (Eamon, 2001), SES (Yoshikawa et al., 2012) and birth weight (Hutchinson et al., 2013) were significant predictors of non-cognitive outcomes for children at age 4-5 years, but often only for one or two non-cognitive competencies. With regard to SES, this may be because previous studies had more specific measures of SES than SEIFA. Alternatively, as previously proposed, it may also be that what parents do is more important than parents' means. When considering maternal age there were no significant relationships with conduct problems and peer problems, despite previous research suggesting these as significant relationships (Eamon, 2001). In contrast to Hutchinson et al.'s (2013) findings that birth weight related to parent-reported conduct problems and hyperactivity, birth weight did not significantly predict any non-cognitive outcomes in the current study. While disparities between current and previous results may be spurious or sample-specific, this is unlikely given the size and breadth of current data analyzed for this study. It is also unlikely to be related to highly discrepant means of indexing non-cognitive development, as many studies (especially those larger in scale) tend to rely on adult reports rather than objective measurements. More likely, the current results refine those previous results after considering a broader array of factors and more longitudinal data than is typically examined.

Controlling for these demographic and contextual factors, early non-cognitive development contributed strong and unique explanatory value to subsequent academic outcomes as much as five years later. While each of the non-cognitive variables showed some ability to predict academic outcomes from age 6 to 12 years, early ratings of the child's hyperactive behaviours (at age 4-5 years) was a stronger and more consistent predictor of future academic achievement, across both parent and teacher ratings. To explain, children 
with fewer hyperactive behaviours (those better able to stay on task, control their behaviour, and be less distracted) had better academic outcomes. This is consistent with previous research using objective, direct assessment showing that children with better behavioural self-regulation in preschool tend to achieve higher academic results (Ponitz et al., 2009; von Suchodoletz et al., 2013). Whereas prior studies using self-report (Liem \& Martin, 2011) and other-report methods (Dobbs, Doctoroff, Fisher, \& Arnold, 2006; Sawyer et al., 2014) indicate the independent predictive value of non-cognitive factors on academic outcomes, the current results suggest that these factors provide little explanatory value over and above hyperactivity.

Particularly interesting was the unique predictive strength of teacher ratings of hyperactive behaviours, which was a stronger predictor of later academic outcomes than parental ratings on the same scale. This could be due to the difference in context and points of reference between parents and educators. That is, whereas parents often have more constrained samples from which to gauge whether a behaviour is common or frequent (e.g., their other children, their children's friends), most educators have much larger reference points from which to make these judgments. This is consistent with Antrop et al.'s (2002) finding of differences between parent and teacher ratings of child behaviour. While research has also established better psychometric properties of teacher-rated SDQ compared to parentrated SDQ (e.g., Stone, Otten, Engels, Vermulst, \& Janssens, 2010), the current study supplements this with important evidence of the stronger predictive validity of teacher ratings in relation to academic outcomes. This has both methodological and practical implications. That is, the current results suggest that parents may often be less equipped to consider their child's behaviour in relation to that of a broader same-age population. This has potential implications for parental interventions and programs targeting children's behavioural, social, and emotional development. Specifically, the most effective programs require accurate 
matching of provision to children's objective developmental progress and needs. In addition to the program content, these programs thus may further benefit from developing parents' knowledge of child development and key milestones, formative assessments, and how to tailor program practices and approaches to their child's developmental progress.

All other non-cognitive factors also predicted later academic outcomes, albeit with less consistency and strength of prediction. For instance, early peer problems and prosocial behaviour predicted receptive vocabulary, literacy and numeracy, consistent with findings that socially competent and adaptive children achieve better academic results (Caprara et al., 2000; Dobbs et al., 2006). However, these factors were highly inconsistent in their predictive strength, which reinforces the primacy of hyperactive behaviours for predicting the academic outcomes examined.

It is noted that the current study was constrained by the longitudinal data and variables available across the two LSAC cohorts. While this dataset is expansive and broadly interdisciplinary, much of the data is self- or other-report in nature. This may be problematic insofar as research suggests potential discontinuities between reported perceptions and actual behaviour (Faulkner, Solomon, Berry, Deshpande, \& Latimer-Cheung, 2014). This is seen here in the disparity between educator- and parent-rating of the frequency of children's noncognitive behaviours (and also evidenced in multiple other studies; Antrop et al., 2002; Hinshaw et al., 1992). That said, subjective reports permit collection of large, geographically dispersed, and nationally representative data that otherwise would have been difficult to collect. As such, while replication of these findings with more direct measures is warranted, the current results nevertheless provide a broader picture of these associations than direct measurement studies would find feasible. There were also differing levels of missing data across variables, which were not imputed because the prevalence of missing data for some variables made this a problematic option. Nevertheless, this may have resulted in non- 
representativeness in the population. In addition, the current study intentionally performed discrete analyses to (1) investigate the antecedents of social, emotional and behavioural development; and (2) investigate the predictive strength of these non-cognitive factors in predicting academic performance. This was because there was a constrained basis from which to make a priori hypotheses of these complex, multiple-measurement variables. As such, this study provides important suggestions of the concurrent relationships that might be modeled using more sophisticated, multivariate approaches. Lastly, this study adopted a significance level of $p=.05$, and as such care needs to be taken in the interpretation of the findings (Sterne \& Smith, 2001). Indeed, effect sizes (e.g., standardised beta weights), consistency of prediction across outcomes, and support from replication should be interpreted alongside significance levels. When doing this, the core findings appear to remain intact: that hyperactivity remains the strongest and most consistent predictor of academic outcomes, and that teacher ratings appear to provide a better index for this prediction.

Taken together, the current findings replicate, refute, and extend prior findings, in a younger age group and a larger longitudinal sample. That is, while a number of previous relationships were supported in the current study (e.g., hyperactivity and SES on academic achievement), the current findings also contradict evidence of the independent importance of many additional factors (e.g., birth weight, peer problems). Specifically, the current study shows that early hyperactive behaviours (at age 4-5 years) provide the strongest and most consistent prediction of later academic outcomes (until at least 10-11 years of age).

Additionally, the current study suggests that early hostile parenting styles are also associated with early non-cognitive development, which may only indirectly influence child academic achievement. In contrast, parental education, and maternal education in particular, predicted non-cognitive and academic outcomes, suggesting direct and indirect effects. These results suggest that non-cognitive development is at least partly associated with many modifiable 
environmental factors, and thus may be viable and worthy targets for early prevention (e.g. parenting programs) and education programs (e.g. early childhood educator training). The current results also suggest that these programs should consider the potentially constrained knowledge and reference points of parents, suggesting the need for stronger links to home environments to support parents' understandings of child development, providing tailored educational experiences and linking to available supports. Cutting across this is the need to consider not only cognitive aspects of children's development, but also their non-cognitive development. 


\section{References}

ACARA. (2013). NAPLAN National Assessment Program Literacy and Numeracy. Retrieved from http://www.nap.edu.au/naplan/naplan.html

Anthony, L. G., Anthony, B. J., Glanville, D. N., Naiman, D. Q., Waanders, C., \& Shaffer, S. (2005). The relationships between parenting stress, parenting behaviour and preschoolers' social competence and behaviour problems in the classroon. Infant and Child Development, 14, 133-154. doi: 10.1002/icd.385

Antrop, I., Roeyers, H., Oosterlaan, J., \& Van Oost, P. (2002). Agreement between parent and teacher ratings of disruptive behavior disorders in children with clinically diagnosed ADHD. Journal of Psychopathology and Behavioral Assessment, 24(1), 67-73. doi: 10.1023/A:1014057325752

Australian Bureau of Statistics (ABS). (2011). Family Charateristics, Australia 2009- 2010. Retreived from http://www.abs.gov.au/AUSSTATS/abs@.nsf/Previousproducts/4442.0Main\%20Feat ures2209-10.

Australian Institute of Family Studies (AIFS). (2013). The Longitudinal Study of Australian Children Data User Guide - November 2013. Melbourne: AIFS.

Australian Institute of Family Studies (AIFS). (2015). The Longitudinal Study of Australian Children Data User Guide - November 2015. Melbourne: AIFS.

Belsky, J., Bell, B., Bradley, R. H, Stallard, N., \& Stewart-Brown, S. L. (2007). Socioeconomic risk, parenting during the preschool years and child health age 6 years. European Journal of Public Health, 17(5), 508-513. doi: 10.1093/eurpub/ckl261. 
Bradley, R. H., \& Corwyn, R. F. (2002) Socioeconomic status and child development. Annual Review of Psychology, 53, 371-399. doi:

10.1146/annurev.psych.53.100901.135233.

Bussey, K., \& Bandura, A. (1999). Social cognitive theory of gender development and differentation. Psychological Review, 106(4), 676-713.

Caprara, G. V., Barbaranelli, C., Pastorelli, C., Bandura, A., \& Zimbardo, P. G. (2000). Prosocial foundations of children's academic achievement. Psychological Science, 11(4), 302-306.

Carneiro, P., Crawford, C., \& Goodman, A. (2007) The impact of early cognitive and noncognitive skills on later outcome (CEE DP 92). London: Centre for the Economics of Education London School of Economics.

Chang, L., Schwartz, D., Dodge, K. A., \& McBride-Chang, C. (2003). Harsh parenting in relation to child emotion regulation and agression. Journal of Family Psychology, 4, 598-606. doi: 10.1037/0893-3200.17.4.598.

Clark, A. L., Kochanska, G., Ready, R. (2000). Mothers' personality and its interaction with child temperament as predictors of parenting behavior. Journal of Personality and Social Psychology, 79(2), 274-285. doi:10.1037/0022-3514.79.2.274.

Clarke, B. L., Sheridan, S. M., Kim, E. M., Kupyk, K. A., Knoche, L. L., \& Sjuts, T. M. (2012). School readiness outcomes for preschool children at risk: A randomized trial of parent engagement intervention and the role of parental depression (CYFS Working Paper No. 2012-5). Lincoln, NB: University of Nebraska.

Davis-Kean, P. E. (2005). The influence of parent education and family income on child achievement: The indirect role of parental expectations and the home environment. Journal of Family Psychology, 19(2), 294-304. 
Dobbs, J., Doctoroff, G. L., Fisher, P. H., \& Arnold, D. H. (2006). The association between preschool children's socio-emotional functioning and their mathematical skills. Applied Developmental Psychology, 27, 97-108. doi: 10.1016/appdev.2005.12.008

Dunn, L. M., \& Dunn, L. M. (1997). PPVT-III: Peabody Picture Vocabulary Test. Circle Pines, MN: American Guidance Service.

Eamon, M. K. (2001). Antecedents and socioemotional consequences of physical punishment on children in two parent families. Child Abuse \& Neglect, 6, 787-802. doi: $10.1016 / \mathrm{S} 0145-2134(01) 00239-3$

Evans, G. W., \& English, K. (2002). The environment of poverty: Multiple stressor exposure, psychophysiological stress, and socioemotional adjustment. Child Development, 73(4), 1238-1248. doi: 10.1111/1467-8624.00469

Faulkner, G., Solomon, V., Berry, T., Deshpande, S., \& Latimer-Cheung, A. E. (2014). Examining the potential disconnect between parents' perceptions and reality regarding the physical activity levels of their children. Journal of Applied Research on Children: Informing Policy for Children at Risk, 5(1), 1-27.

Foster, M. A., Lambert, R., Abbott-Shim, M., McCarty, F., \& Franze, S. (2005). A model of home learning environment and social risk factors in relation to children's emergent literacy and social outcomes. Early Childhood Research Quarterly, 20(1), 13-36. doi:10.1016/j.ecresq.2005.01.006

Gardner, F., Johnson, A., Yudkin, P., Bowler, U., Hockley, C., Mutch, L., \& Wariyar, U. (2004). Behavioral and emotional adjustment of teenagers in mainstream school who were born before 29 weeks gestation. Pediatrics, 114(3), 676-682. doi:10.1542/peds2003-0763-L. 
Geronimus, A. T., Korenman, S., \& Hillemeier, M. (1994). Does young maternal age adversely affect child development? Evidence from cousin comparisons in the United States. Population and Development Review, 20(3), 585-609.

Goodman, R. (1997). The Strengths and Difficulties Questionnaire: A research note. Journal of Child Psychology and Psychiatry and Allied Disciplines, 38(5), 581-586.

Goodman, R. (2001). Psychometric properties of the Strengths and Difficulties Questionnaire. Journal of the American Academy of Child and Adolescent Psychiatry, 40(11), 1337-1345.

Gray, R. F., Indurkhya, A., \& McCorrmick, M. C. (2004). Prevalence, stability and predictors of clinically significant behavior problems in low birth weight children at 3,5 , and 8 years of age. Pediatrics, 114(3), 736-743. doi:10.1542/peds.2003-1150-L.

Grolnick, W. S., \& Ryan, R. M. (1989). Parent styles associated with children's selfregulation and competence in school. Journal of Educational Psychology, 81(2), 143154.

Gross, J. J. (1998). The emerging field of emotion regulation: An integrative review. Review of General Psychology, 2(3), 271-299.

Harpin, V. (2005). The effect of ADHD on the life of an individual, their family and community from preschool to adult life. Archives of Disease in Childhood, 90(1), 2-6. doi: 10.1136/abx2004.059006.

Heckman, J. J., Stixrud, J., \& Urzua, S. (2006) The effects of cognitive and noncognitive abilities on labor market outcomes and social behaviour. Journal of Labor Economics, 24(3), 411-482.

Henricsson, L., \& Rydell, A. (2006). Children with behaviour problems: The influence of social competence and social relations on problem stability, school acheivement and 
peer acceptance across the first six years of school. Infant and Child Development, 15, 347-366. doi: 10.1002/ics.448.

Hinshaw, S. P., Han, S. S., Erhardt, D., \& Huber, A. (1992). Internalizing and externalizing behavior problems in preschool children: Correspondence among parent and teacher ratings and behavior observations. Journal of Clinical Child Psychology, 21(2), 143150.

Horn, W. F., \& Packard, T. (1985). Early identification of learning: A meta-analysis. Journal of Educational Psychology, 77(5), 597-607.

Howse, R. B., Lange, G., Farran, D. C., \& Boyles, C. D. (2003). Motivation and selfregulation as predictors of achievement in economically disadvantaged young children. The Journal of Experimental Education, 71(2), 151-174.

Hutchinson, E. A., De Luca, C. R., Doyle, L. W., Roberts, G., \& Anderson, P. J. (2013). School-age outcomes of extremely preterm or extremely low birth weight children. Pediatrics, 131(4), e1053-e1061.

Liem, G. A. D., \& Martin, A. J. (2011). Peer relationships and adolescents academic and nonacademic outcomes: Same-sex and opposite sex peer effects and the mediating role of school engagement. British Journal of Educational Psychology, 81, 183-206. doi: 10.1111/j.2044-8279.2010.02013.x

Loe, I. M., \& Feldman, H. M. (2007). Academic and educational outcomes of children with ADHD. Journal of Pediartic Psychology, 32(6), 643-654.

Maguire, L. K., Niens, U., McCann, M., \& Connolly, P. (2016). Emotional development among school-age children: Gender differences in the role of problem behaviours. Educational Psychology, 36(8), 1408-1428. doi:10.1080/01443410.2015.1034090

Malecki, C. K., \& Elliot, S. N. (2002). Children's social behaviors as predictors of academic achievement: A longitudinal analysis. School Psychology Quarterly, 17(1), 1-23. 
McLoyd, V. C. (1998). Socioeconomic disadvantage and child development. American Psychologist, 53(2), 185-204.

Miller, L. S., Koplewicz, H. S., \& Klein, R. G. (1997). Teacher ratings of hyperactivity, inattention and conduct problems in preschoolers. Journal of Abnormal Child Psychology, 25(2), 113-119. doi: 10.1023/A:1025727428097

Nicholson, J. S., Deboeck, P. R., \& Howard, W. (2017). Attrition in developmental psychology: A review of modern missing data reporting and practices. International Journal of Behavioural Development, 41(1), 143-153. doi: $10.1177 / 0165025415618275$.

Pink, B. (2013). Socio-Economic Indexes for Areas (SEIFA) 2011. Canberra, ACT: Australian Bureau of Statistics.

Ponitz, C. C., Matthews, J. S., \& Morrison, F. J. (2009). A structured observation of behavioral self-regulation and its contribution to kindergarten outcomes. Developmental Psychology, 45(3), 605-619. doi: 10.1037/a0015365

Raver, C. C., Jones, S. M., Li-Grining, C., Zhai, F., Bub, K., \& Pressler, E. (2011). CSRP's impact on low income preschoolers' preacademic skills: Self-regulation as a mediating mechanism. Child Development, 82(1), 362-378. doi:10.1111/j.14678624.2010.01561.x

Rosenthal, D. G., \& Weitzman, M. (2011). Examining the effects of intrauterine and postnatal exposure to tobacco smoke on childhood cognitive and behavoral development. International Journal of Mental Health, 40(1), 39-64. doi:10.2753/IMH020-7411400103.

Rothon, C., Head, J., Clark, C., Klineberg, E., Cattell, V., \& Stansfeld, S. (2009). The impact of psychological distress on the educational acheivement of adolescents at the end of 
compulsor education. Social Psychiatry and Psychiatric Epidemiology, 44(5), 421427. doi: 10.1007/s00127-008-0452-8.

Sammons, P., Sylva, K., Melhuish, E., Siraj-Blatchford, I., Taggart, B., \& Hunt, S. (2008). Influences on children's attainment and progress in key stage 2: Cognitive outcomes in year 6 (Research Report DCSF-RR048). Nottingham, UK: DCSF.

Sawyer, A. C. P., Chittleborough, C. R., Mittinty, M. N., Miller-Lewis, L. R., Sawyer, M. G., ... \& Lynch, J. W. (2014). Are trajectories of self regulation abilities from ages 2-3 to 6-7 associated with academic achievement in the early school years. Child: Care Health and Development, 41(5), 774-754. doi: 10.111/cch.12208

Sharp, C., Croudance, T. J., Gooyer, I. M., \& Antmann, D. (2005). The strength and difficulties questionnare: Predictive validity of parent and teacher ratings for helpseeking behaviour over one year. Educational and Child Psychology, 22(3), 28-44.

Shochet, I. M., Dadds, M. R., Ham, D., \& Montague, R. (2006). School connectedness is an underemphasized parameter in adolescent mental health: Results of a community prediction study. Journal of Clinical Child \& Adolescent Psychology, 35(2), 170-179. doi: 10.1207/s1534424jccp3502_1.

Sirin, S. R. (2005). Socioeconomic status and academic acheivement: A meta-analytic review. Review of Educational Research, 75(3), 417-453.

Soloff, C., Lawrence, D., \& Johnstone, R. (2005). LSAC Technical Paper No. 1: Sample design. Melbourne, VIC: Australian Institute of Family Studies.

Stergiakouli, E., Martin, J., Hamshere, M. L., Heron, J., St Beate, P., Timpson, N. J., ... Smith, D. G. (2016). Association between polygenic risk scores for attention-deficit hyperactivity disorder and educational and cognitive outcomes in the general population. International Journal of Epidemiology, 46(2), 421-428. doi: 10.1093/ije/dyw216 
Sterne, J. A. C., \& Smith, G. D. (2001). Sifting the evidence. British Medical Journal, 332, 226-231.

Stone, L. L., Otten, R., Engels, R. C. M. E., Vermulst, A. A., \& Jannsens, J. M. A. M. (2010). Psychometric properties of the parent and teacher versions of the strengths and difficulties questionnaire for 4 to 12 year olds: A review. Clinical Child and Family Psychological Review, 13, 245-274. doi: 10.1007/s10567-010-0071-2

Tabachnick, B., \& Fidell, L. (2013). Using multivariate statistics. Hoboken, NJ: Pearson.

Taylor, E., Chadwick, O., Heptinstall, E., \& Danckaerts, M. (1996). Hyperactivity and conduct problems as risk factors for adolescent development. Journal of American Academy of Child and Adolescent Psychiatry, 35(9), 1213-1226. doi:

$10.1097 / 00004583-199609000-00019$

Trentacosta, C. J., \& Shaw, D. S. (2009). Emotional self-regulation, peer rejection and antisocial behavior: Developmental associations from early childhood to early adolescence Journal of Applied Developmental Psychology, 30, 356-365. doi:10.1016/j.appdev.2008.12.016

Von Suchodoletz, A., Gestsdottir, S., Wanless, S. B., McClelland, M. M., Birgisdottir, F., Gunzenhauser, C., \& Ragnarsdottir, H. (2013). Behavioral self-regulation and relations to emergent academic skills among children in Germany and Iceland. Early Childhood Research Quarterly, 28(1), 62-73.

Yoshikawa, H., Aber, J. L., \& Beardslee, W. R. (2012). The effects of poverty on the mental, emotional, and behavioral health of children and youth. American Psychologist, 67(4), 272-284. doi: 10.1037//a002 